pretative comments are most helpful. The contributors have also occasionally been permitted useful afterthoughts.

Contemporary notions of receptor theory and recognition mechanisms are thoroughly aired and the concept of immunological surveillance (and its failure) in relation to tumour growth is discussed in a singularly clear manner in the session chaired by R. S. Schwartz and introduced by K. E. Hellström. The discussions are revealed as lively and one is grateful for the fact that several times participants are recorded as unable to understand the points at issue. There is a mildly self-congratulatory air about the meeting but this is fitting and one must agree with Chairman Smith (p. 47) that the affair was an intellectual tour de force.

The book is suitable for purchase by the libraries of all interested institutes and for the bedsides of dedicated individuals It is well laid out with good summaries of session topics in a manner engagingly similar to that adopted at the beginning of chapters in Victorian novelettes. There is no index or references.

$$
\text { A. J. S. Davies }
$$

\section{Soil and Water}

Soil and Water : Physical Principles and Processes. By Daniel Hillel. (Physiological Ecology: a Series of Monographs and Treatises.) Pp. xiv +288 . (Academic: New York and London, January 1971.) $\$ 14$; £6.55.

THrs presentation of the fundamental physical principles governing the soil water system is intended for students of soil physics and for workers in a variety of disciplines for whom soil water is important. Part I covers the basic principles of soil and water, the physics of the state of water in the soil and its flow in saturated and unsaturated systems. Part II discusses the field water cycle, covering infiltration, redistribution of water in the soil profile, ground water drainage, evaporation, water removal by plants and the effect of energy balance on water balance. Appendices by C. R. Amerman and E. E. Miller describe methods of solving the flow equation. Over 400 references are collected at the end.

Hillel's treatment of this complex subject is didactic and clear, assisted by a number of schematic diagrams, but it is rather condensed so that there is little space for critical discussion. Brevity occasionally obscures comprehension, and the diagram on p. 76 is misleading in suggesting that a hanging water column is the normal way of applying 1 bar suction to a tension plate, but fortunately these lapses are rare.

The approach is thermodynamic: potential is the vital statistic of soil water. Hillel recognizes that a newcomer to the field may be confused by the variety of units and symbols by which potential is expressed (five different pressure units occur in the book) but he missed the opportunity to give a lead in rationalizing these and relating them to SI units. The use of the term "wetness" for water content seems inappropriate, for it is not conventional and its subjective associations relate more to potential than to water content. Arbitrary soil water "constants" such as field capacity and wilting point are shown to have little physical significance, but it is a pity that in presumably abandoning the useful concept of available water capacity, no guidance is given on a more acceptable measure of the storage capacity of a soil profile.

These are relatively minor criticisms, and on the whole the book succeeds in its aim and should prove to be a valuable introductory text. It covers a wider subject matter and is more readable than E. C. Childs's book on soil water phenomena, but within its limits the latter both explains the physics better and deals with problem solving in more detail.

B. W. BACHE

\section{Solids in the Infrared}

Far-Infrared Properties of Solids. Edited by S. S. Mitra and S. Nudelman. (Proceedings of a NATO Advanced Study Institute, held in Delft, Netherlands, August 5-23, 1968.) (Optical Physics and Engineering.) Pp. viii +605 . (Plenum: New York and London, 1970.) $\$ 25$.

THIs book presents the lectures given at a summer school in 1968 and is for postgraduate students of the solid state. Techniques of far infrared spectrometry (interferometric) are covered as are some particular aspects of the techniques of Raman spectroscopy which are relevant to very low frequency excitations. The most useful part of the book, however, is probably the middle section where in four chapters (out of nineteen) the main areas of solid state physics in which far infrared spectroscopy has been fruitful-magneto-optical effects due to free carriers in semiconductors, spin-wave and other excitations in magnetic solids, lattice vibrations in ionic crystals which order ferroelectrically, electronic excitations in superconductors-are reviewed. The other chapters take up more specialized topics and the treatment varies considerably.

D. H. MARTIN

\section{Cardiology}

Auscultation of the Heart and Phonocardiography. By Aubrey Leatham. Pp. 151. (J. and A. Churchill: London, 1970.) $£ 4.00$.

THIs excellent monograph is a comprehensive account of auscultation of the heart and is a record of the author's extensive researches into this subject. The basic principles of auscultation and phonocardiography are dealt with in the first chapter and subsequent ones are concerned with the sound events in the cardiac cycle in health and disease. Various related problems are critically discussed and well illustrated by photographically recorded phonocardiograms. This book can be recommended for medical students and postgraduates but it is clear that the author assumes that the reader has considerable knowledge of cardiology. Leatham's book may be considered an important contribution to the literature on cardiovascular disease. The printing, illustrations and paper are of the highest order, references adequate although relatively few and it is recommended as an authoritative dissertation on this subject. The index, however, is short for a reference book with so much factual information. W. BRIGDEN

\section{Quaternary Quarterly}

Quaternary Research: an Interdisciplinary Journal. Edited by A. L. Washburn and Joe S. Creager. Vol. 1, No. 1: Pp. 132. (Academic: New York and London, September 1970.) $\$ 10.00$ each volume.

THIS is the first number of a new periodical, to be issued four times a year, and costing $\$ 30$ per year for institutions and $\$ 10$ for personal subscribers. The subject of quaternary research is wide, covering all aspects of environmental history in the past two million years or so. A number of periodicals already cater for the same field, and I doubt whether there is a further need for yet another journal. In such an interdisciplinary subject as quaternary research, there are advantages in bringing together different facets of the same subject under the cover of one journal; advances on the subject can be kept under surveillance and they are more readily accessible to the reader than if they were dispersed in the journals of parent disciplines. On the other hand, the concentration into such an interdisciplinary journal may result in the separation of quaternary disciplines from their parent subjects, which is to be regretted because it is important that the relevance of quaternary research to these parent subjects should remain in front of readers of journals devoted to those parent subjects. The first issue of the journal contains articles on a wide variety of subjects, from quaternary meteorology to stratigraphy, thermokarst and tephrochronology. Some of the articles are reviews, which could be useful to quaternary researchers-certainly a better service than provided by over specialized articles. If a high standard can be maintained, the journal will certainly be most welcome. R. G. WEST 